\title{
Prediction of recurrence in low and intermediate risk non-muscle invasive bladder cancer by real-time quantitative PCR analysis: cDNA microarray results
}

\author{
J. MARES ${ }^{1, *}$, M. SZAKACSOVA², V. SOUKUP² ${ }^{2}$ J. DUSKOVA ${ }^{3}$, A. HORINEK ${ }^{4}$, M. BABJUK ${ }^{5}$ \\ ${ }^{1}$ Institute of Biology and Medical Genetics, 2nd Faculty of Medicine, Charles University, V Uvalu 84, 15000 Prague 5, Czech Republic, ${ }^{2}$ Department \\ of Urology, General Teaching Hospital and 1st Faculty of Medicine, Charles University, Ke Karlovu 6, 12000 Prague 2, Czech Republic, ${ }^{3}$ Department \\ of Pathological Anatomy, General Teaching Hospital and 1st Faculty of Medicine, Charles University, Studnickova 2, 12000 Prague 2, Czech Republic, \\ ${ }^{4}$ Institute of Biology and Medical Genetics, General Teaching Hospital and 1st Faculty of Medicine, Charles University, Albertov 4, 12000 Prague 2, Czech \\ Republic, ${ }^{5}$ Department of Urology, 2nd Faculty of Medicine, Charles University, Hospital Motol, V Uvalu 84, 15000 Prague 5, Czech Republic
}

${ }^{*}$ Correspondence: jaroslav.mares@lfmotol.cuni.cz

Received May 18, 2012 / Accepted January 16, 2013

\begin{abstract}
The aim of the study was to define specific genetic profile in Ta and T1 urinary bladder carcinoma patients with and without recurrence by gene expression microarrays. Eleven patients with the time to recurrence shorter than one year (patients with recurrence) and 11 patients with time to recurrence longer than 4 years (patients without recurrence) were enrolled.

Data from microarrays were subjected to a panel of statistical analyses to identify bladder cancer recurrence-associated gene signatures. Initial screening using the GeneSpring and Bioconductor software tools revealed a putative set 47 genes differing in gene expression in both groups. After the validation, 33 genes manifested significant differences between both groups. The significant expression was observed in the group of patients without recurrence by 30 genes of which the highest differences were detected by ANXA1, ARHGEF4, FLJ32252, GNE, NINJ1, PRICKLE1, PSAT1, RNASE1, SPTAN1, SYNGR1, TNFSF15, TSPAN1, and WDR34. These genes code for signal transduction, vascular remodeling and vascular endothelial growth inhibition mainly. In the group with recurrence, 3 genes had significant differences, the highest differences were identified by two genes (PLOD2 and WDR72).

Loci of genes with significant changes of gene expression were located on characteristic chromosomes for bladder cancer: 7 loci on chromosome 9, 8 loci on chromosomes 1,2,3,12, 14, 15, 16, and 22 .

We have selected and validated 15 genes that are differentially expressed in superficial bladder cancer. We hope that this cohort of genes will serve as a promising pool of candidate biomarkers for early stage bladder cancer. Our results indicate that it may be possible to identify patients with a low and high risk of disease recurrence at an early stage using a molecular profile.
\end{abstract}

Key words: bladder cancer, non-muscle invasive urothelial tumors, gene expression microarrays

Bladder cancer (BC) is the sixth most frequent solid tumor in men and thirteenth in women in Czech Republic with 1827 and 650 new cases in 2005, respectively [1] and 375.000 new cases and 145.000 deaths worldwide annually [2]. Urothelial carcinoma (UC) is a heterogenous neoplasm manifesting either non-muscle invasive bladder cancer (NMIBC) - Ta, T1 and Tis by approximatelly $75 \%$ newly diagnosed cases or muscle invasive (T2-T4) and metastatic tumor $(25 \%)[3,4]$. After initial treatment of NMIBC by transurethral resection (TURB) up to $80 \%$ of patients develop recurrences. From $10 \%$ to $15 \%$ of them progress to muscle invasive cancer $[5,6]$. For treatment and follow up of patients it is crucial to predict the recurrence and progression potential of non-muscle invasive bladder cancer. Therefore new methods are engaged to identify new prognostic markers based on the molecular nature of the tumor development and recurrence $[7,8]$.

The objective of our study was to identify the genes differing in gene expression in tumors with and without recurrence. Among the genes it might be determined a gene or several genes serving as factors for further diagnostic test development.

\section{Patients and methods}

Patients and tissue samples. In total 22 primary Ta and T1 NMIBC with low and intermediate risk of recurrence 
were selected from bladder tumor collections of the bladder tumor biobank of the Department of Urology of the Charles University in Prague. All patients, signed informed consent for use of the tissue samples and analysis of relevant clinicopathologic data. In all patients, complete transurethral resection of all visible lesions was performed from the year 2000 to 2005 . The tumor samples were frozen immediately after surgery and stored at $-80^{\circ} \mathrm{C}$. Histological examination was performed by experienced histopathologist (JD). Tumors were classified according to the TNM (Tumor-Node-Metastasis) system [9]. For histologic grade assessment the Word Health Organization criteria from 1973 (WHO 1973) were used [9] (Table 1). Tumors selected were from 11 patients who recur between 6-12 months after TURB (patients with recurrence) and from 11 patients with time to recurrence longer than 4 years, if ever (patients without recurrence). None of the patients was treated with intravesical mitomycin-C or BCG (Bacillus Calmette-Guerin) vaccine. All patients were followed afterwards according to routine schemes including regular cystoscopies and cytologies. Biopsy or TURB were indicated in all cases with suspect cystoscopy or positive urinary cytology, all recurrences were histologically confirmed. All patients involved in this study were Caucasians of Central Europe.

RNA isolation, hybridization and microarray scanning. Total RNA from crude tumor biopsy was extracted according to Applied Bioassays guidelines using the ABI Prism $6100 \mathrm{Nu}$ cleic Acid Prepstation. Isolated RNA quality and integrity was checked by the spectrometer Nanodrop ND-1000 and Agilent 2100 Bioanalyzer (criteria: RIN (RNA integrity number) $>7$, 28S/18S >1).

Applied Biosystems Human Genome Survey Arrays V2.0 were used to determine the transcriptional profiles of 29,098 targets. Array hybridization, chemiluminescence detection, image acquisition and analysis were performed using Applied Biosystems Chemiluminescence Detection Kit and Applied Biosystems 1700 Chemiluminescence Microarray Analyzer following the manufacturer's instructions.

Data analysis using GeneSpring Expression Analysis 7.3.1 tool. Data were normalized to the $50^{\text {th }}$ percentile (intraarray normalization) and each gene was normalized to the median expression (inter-array normalization). Data were pre-filtered based on the signal to noise ratio (cut-off level: signal above noise $>3$-fold in 6 out of 11 arrays in all samples of the respective biological replicate group) and non-changing genes (normalized expression levels from 0.667 to 1.334) were subtracted. The remaining data set was tested for differentially expressed genes using ANOVA (Analysis of variance) method (GeneSpring Expression Analysis 7.3.1 tool, Agilent Technologies). A p-value of $\mathrm{p}<0.05$ (Welch $\mathrm{t}$-test) was considered significant. Expression differences of at least two-fold were considered relevant.

Table 1. Patient clinical data

\begin{tabular}{|c|c|c|c|c|c|c|c|}
\hline Case number & Recurrence & Gender & Age & $\begin{array}{c}\text { Stage } \\
\mathrm{T}\end{array}$ & Grade & $\begin{array}{l}\text { Tumor size } \\
(\mathrm{cm})\end{array}$ & $\begin{array}{c}\text { Single/multiple } \\
\text { tumor }\end{array}$ \\
\hline 3 & $\mathrm{~N}$ & $\mathrm{~F}$ & 47 & $\mathrm{a}$ & 2 & 4.00 & $\mathrm{M}$ \\
\hline 15 & $\mathrm{Y}$ & M & 74 & $\mathrm{a}$ & 2 & 3.00 & M \\
\hline 38 & $\mathrm{~N}$ & $\mathrm{~F}$ & 72 & 1 & 2 & 2.00 & $\mathrm{M}$ \\
\hline 46 & $\mathrm{Y}$ & M & 57 & $\mathrm{a}$ & 2 & 7.00 & $\mathrm{~S}$ \\
\hline 49 & $\mathrm{Y}$ & $\mathrm{F}$ & 71 & $\mathrm{a}$ & 1 & 8.00 & $S$ \\
\hline 50 & $\mathrm{Y}$ & M & 71 & $\mathrm{a}$ & 2 & 3.00 & M \\
\hline 55 & $\mathrm{Y}$ & $\mathrm{M}$ & 63 & 1 & 2 & 2.00 & $\mathrm{M}$ \\
\hline 56 & $\mathrm{~N}$ & $\mathrm{~F}$ & 62 & $\mathrm{a}$ & 3 & 2.00 & M \\
\hline 66 & $\mathrm{~N}$ & M & 52 & $\mathrm{a}$ & 2 & 5.50 & $\mathrm{~S}$ \\
\hline 80 & $\mathrm{~N}$ & M & 71 & $\mathrm{a}$ & 2 & 7.00 & M \\
\hline 81 & $\mathrm{Y}$ & $\mathrm{F}$ & 81 & $\mathrm{a}$ & 2 & 2.00 & $\mathrm{M}$ \\
\hline 99 & $\mathrm{Y}$ & M & 44 & $\mathrm{a}$ & 1 & 3.00 & $S$ \\
\hline 113 & $\mathrm{~N}$ & M & 72 & $\mathrm{a}$ & 2 & 1.50 & M \\
\hline 134 & $\mathrm{Y}$ & M & 65 & $\mathrm{a}$ & 2 & 1.50 & M \\
\hline 146 & $\mathrm{~N}$ & M & 43 & $\mathrm{a}$ & 1 & 2.00 & $\mathrm{~S}$ \\
\hline 156 & $\mathrm{~N}$ & $\mathrm{~F}$ & 52 & $\mathrm{a}$ & 1 & 4.00 & S \\
\hline 228 & $\mathrm{~N}$ & M & 60 & $a$ & 2 & 4.00 & $\mathrm{~S}$ \\
\hline 233 & $\mathrm{Y}$ & M & 47 & $\mathrm{a}$ & 1 & 8.00 & $\mathrm{M}$ \\
\hline 235 & $\mathrm{Y}$ & M & 71 & 1 & 2 & 2.00 & M \\
\hline 250 & $\mathrm{~N}$ & M & 72 & $\mathrm{a}$ & 2 & 3.00 & $\mathrm{M}$ \\
\hline 254 & $\mathrm{~N}$ & $\mathrm{M}$ & 70 & $\mathrm{a}$ & 1 & 8.00 & $\mathrm{M}$ \\
\hline 272 & $\mathrm{Y}$ & $\mathrm{M}$ & 56 & $\mathrm{a}$ & 1 & 2.50 & M \\
\hline
\end{tabular}

$\mathrm{Y}=$ with recurrence, $\mathrm{N}=$ without recurrence, $\mathrm{F}=$ female, $\mathrm{M}=$ male 
Analysis of microarray data. Two different filtering strategies were used in our study. The first strategy selected genes from both groups that show a signal/noise $(\mathrm{S} / \mathrm{N})$ ratio $>3$-fold in all 11 arrays. The second strategy was less stringent: cut-off level: signal above noise $>3$-fold in 6 out of 11 arrays in all samples of the respective biological replicate group.

Validation. To technically validate microarray gene expression data of 47 the most differentially expressed genes were analyzed in the same RNA samples used to hybridize microarrays. RNAseI, GAPDH and HPRT were used as house-keeping genes. Real-time reverse transcriptase PCR gene expressions studies were performed on 7900HT Fast Real Time PCR (Applied Biosystems, USA) in the Custom TaqMan ${ }^{\circledR}$ Low Density Array (TLDA), (Applied Biosystems, USA).

Two patient groups were tested: A (with recurrence) and $B$ (without recurrence). Two tail unpaired t-test was used for analysis of statistical significance of relative expression of tested genes between these groups. Results showing P-values less than 0.05 were considered statistically significant.

\section{Results}

Clinicopathologic characteristics. Clinical and histopatologic data for patients included to this study are listed in Table 1 . Total of 22 primary non-muscle invasive bladder tumors were analyzed, including 19 stage pTa and 3 pT1. All T1 tumors had only superficial lamina propria invasion (T1a), the deep resection including detrusor muscle confirmed the absence of deeper tumor invasion. Two sets of tissue were analyzed from patients with recurrence and without recurrence, respectively.

Expression profiles and differential gene expression. As the principal objective of the present report it was to determine differences in gene expression between those clinical subtypes of UC. Therefore we did not analyze any normal urothelial samples in the pools.

After microarray processing genes with at least a 2.0 -fold difference in expression between cases with and without recurrence were considered significant for expression analysis. After subtracting non-changing ones, only 1,137 genes were used for statistical analysis. From this pool 185 significantly regulated genes were identified. There were statistically significant differences in the gene expression between two clinical groups of UC. A significant up-regulation of 85 genes was evident in group without recurrence and a significant up-regulation of 23 genes in group with recurrence (in both groups 2 -fold change).

Real-time reverse transcriptase PCR validation. According to the Applied Biosystems protocol, the same mRNA used in the microarray analysis was amplified by 47 candidate genes and by 3 housekeeping genes. Figure 1 shows significant differences in relative gene expression of 47 genes, as resulted from microarray studies. The most prominent significant differences showed genes PLOD2, and WDR72 in the group with recurrence and PSAT1, PRICKLE1, TSPAN1, NINJ1, FLJ32252, GNE, ANXA1, ARHGEF4, TNFSF15, WDR34, RNASE1, SYNGR1, and SPTAN1 genes of the group without recurrence.

The Table 2 lists differential up-regulation of genes in both groups after validation with at least a threefold change in comparison between both groups (without and with recurrence). Fifteen genes showed at least a threefold change in expression between the patient group without recurrence and with recurrence and vice versa (by genes PLOD2 and WDR72). Genes involved in the Table 2 participate in signal transduction, anti-inflammatory activity, cell adhesion, cell cycle progression, apoptosis, gene regulation and surprisingly neural function.

Table 2. The most differentially expressed genes in tumors differing in the presence or absence of recurrence: results of RT-PCR in real time

\begin{tabular}{|c|c|c|c|c|c|}
\hline Number & Gene & Description & Accession number & $\begin{array}{l}\text { Fold } \\
\text { expression }\end{array}$ & Location \\
\hline 1 & PSAT1 & phosphoserine aminotransferase 1 & Hs00253548_m1 & 17.3 & $9 \mathrm{q} 21.2$ \\
\hline 2 & PRICKLE1 & prickle homolog 1 (Drosophila) & Hs01055551_m1 & 16.2 & $12 \mathrm{q} 12$ \\
\hline 3 & TSPAN1 & tetraspanin 1 & Hs00371661_m1 & 12.3 & $1 \mathrm{p} 34.1$ \\
\hline 4 & NINJ1 & ninjurin 1 & Hs00982607_m1 & 11.7 & $9 \mathrm{q} 22$ \\
\hline 5 & FLJ32252 & hypothetical protein FLJ32252 & Hs01033838_s1 & 11.6 & $16 \mathrm{p} 13.3$ \\
\hline 6 & GNE & glucosamine (UDP-N-acetyl)-2-epimerase/N-acetylmannosamine kinase & Hs00178556_m1 & 11.1 & $9 \mathrm{p} 13.3$ \\
\hline 7 & $A N X A 1$ & annexin $\mathrm{A} 1$ & Hs00167549_m1 & 9.1 & $9 \mathrm{q} 21.13$ \\
\hline 8 & ARHGEF4 & Rho guanine nucleotide exchange factor 4 & Hs00209702_m1 & 8.8 & $2 \mathrm{q} 22$ \\
\hline 9 & TNFSF15 & tumor necrosis factor (ligand) superfamily, member 15 & Hs00270802_m1 & 7.1 & $9 \mathrm{q} 32$ \\
\hline 10 & WDR34 & WD repeat domain 34 & Hs00369329_m1 & 6.8 & $9 \mathrm{q} 34.11$ \\
\hline 11 & RNASE1 & ribonuclease, RNase A family 1 & Hs00379274_m1 & 5.7 & $14 \mathrm{q} 11.2$ \\
\hline 12 & SYNGR1 & synaptogyrin 1 & Hs00377475_m1 & 4.2 & $22 \mathrm{q} 13.1$ \\
\hline 13 & SPTAN1 & spectrin, alpha, non-erythrotic 1 & Hs00162203_m1 & 3.6 & $9 \mathrm{q} 34.11$ \\
\hline 14 & WDR72 & WD repeat domain 72 & Hs00419054_m1 & 5.3 & $15 \mathrm{q} 21.3$ \\
\hline 15 & PLOD2 & procollagen-lysine, 2 -oxoglutarate 5 -dioxygenase 2 & Hs01118190_m1 & 3.6 & $3 q 24$ \\
\hline
\end{tabular}


A

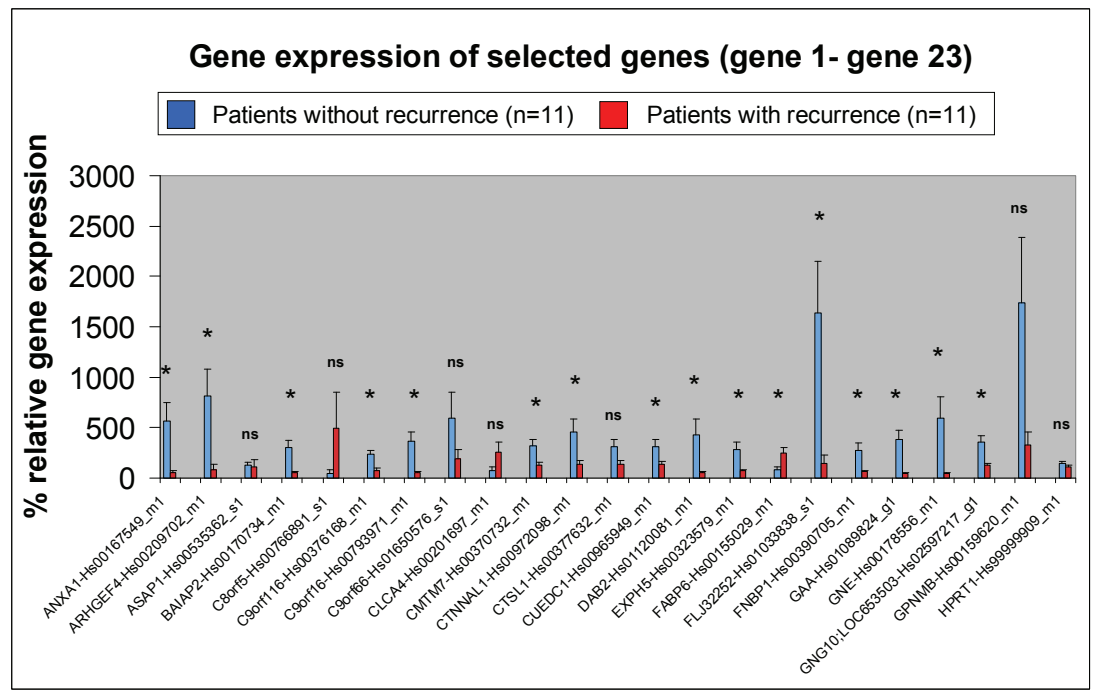

B

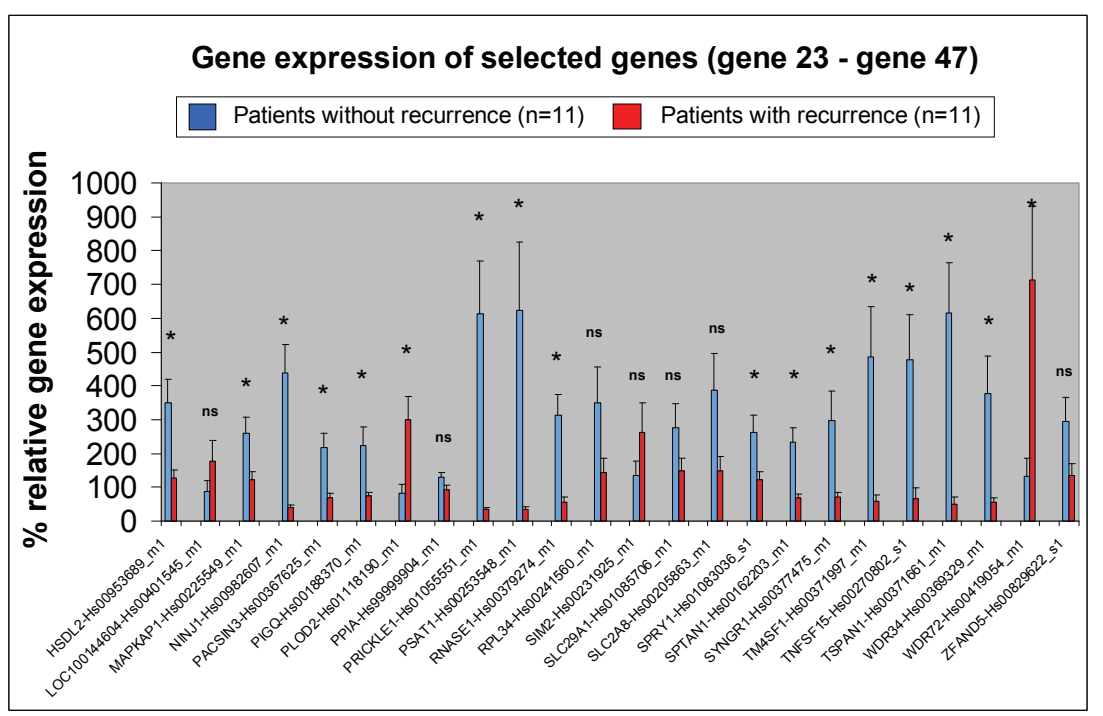

Figure 1. Gene expression of selected genes; A: gene 1 - gene 23; B: gene 23 - gene 47; * significant, ns nonsignificant; RNAseI, GAPDH and HPRT were used as house-keeping genes.

\section{Discussion}

Predicting the probability of bladder cancer recurrence is of great interest in oncological urology. It is anticipated that single molecular markers or combinations of markers can be authorized for the prediction of recurrence or potentially for the prediction of response to therapy. Several expression microarray studies have been performed for prognostic purposes in primary NMIBC, but none has shown sufficient clinical evidence to clinical usage. Most of them are based on identification of genes in transgenic mouse models [10], specific bladder cancer cell lineages [11], biological material from advanced tumors comparing gene expression in invasive stage of tumor disease $[12,13,14]$ or usage of different molecular biological methods [15].

Our findings represent one of the attempts to describe an elaborate gene expression profile in superficial human bladder malignancy. This study is a logic follow-up to identify molecular markers in very early stage of primary NMIBC that may predict its recurrence. If we define upregulated or downregulated genes of our study, several of them are common to genes published by other authors, but in general the analogy of the genes, presented here, is not so extensive with other studies $[7,8,10-16]$. It may be caused by unique provenance 
and sampling of human biological material of both groups of tumors. On the other hand the patient group investigated in this study is ethnically consistent; all patients are Caucasians of Central Europe. Loci of genes with significant changes of gene expression were located on characteristic chromosomes for bladder cancer (7 loci on chromosome 9, 8 loci on chromosomes 1, 2, 3, 12, 14, 15, 16, and 22, see Table 2).

After validation, we describe 15 genes in the present report. The role of only two of them, ANXA1 and NINJ1, related to bladder cancerogenesis, has been studied and published so far $[7,17]$.

Among the gene signatures selected in the present study there are some genes that have not yet been described in bladder tumorigenesis and even in cancer at all (GNE, FLJ32252 and SYNGR1). Their role in bladder carcinogenesis remains unclear. The GNE protein is a key enzyme that triggers and regulates the sialic acid biosynthetic pathway and functions in cellular interactions and signalization [18]. Gene FLJ32252 codes for a noncoding RNA probably and it may have a significance for gene expression regulation. It is not yet known whether the gene SYNGR1, which encodes an integral membrane protein associated with synaptic transmission, is involved into the process of carcinogenesis [19].

The ninjurin 1 (NINJ1) protein demonstrates properties of a homophilic adhesion molecule [7]. We proved on small number of patients that tumors with low NINJ1 expression tend to manifest recurrence than those tumors with higher NINJ1 expression profile. The TNFSF15 gene codes for a cytokine that belongs to the tumor necrosis factor ligand family that acts as a negative regulator of aggressiveness during development of bladder cancer and angiogenesis inhibitor [20]. Expression of the gene TNFSF15 may have a similar protective effect in superficial bladder tumor of the group without recurrence. The PRICKLE1 gene is a negative regulator of Wnt/beta-catenin signaling pathway and a putative tumor suppressor gene in liver cancer [21]. Its low level may have an impact to accelerate recurrence. There are no data available about the role of RNASE1 in bladder cancer, but expected results were obtained for RNASE 1 expression profiles in both groups of our study in the comparison to RNASE1 expression in gastric cancer [22].

There is a set of genes whose role is contradictory in our study and it is difficult to understand the functions of these genes in bladder cancer initiation and recurrence. We found significant expression of the spectrin1 (SPTAN1) in the group without recurrence. Spectrin 1 is a cytoskeletal protein forming a scaffolding and playing an important role in receptor binding, actin crosslinking, maintenance of plasma membrane integrity and cytoskeletal structure [23]. We reported the TSPAN1 gene as a tumor-related gene in bladder cancer for the first time. It has been proposed that TSPAN1 protein, a member of the tetraspanin superfamily, played a role in signal transduction, cell replication and cell abnormal differentiation, but its expression profile is higher in the group without recurrence [24].
Gene ARHGEF4 coding for a Rho GTPase is also a novel factor affecting bladder tumorigenesis. It may modulate many cellular processes that are initiated by G-protein signalization [25]. In our study the gene had higher expression in the group without recurrence. A similar expression profile was found by PSAT1 gene. Its expression was higher by the group without recurrence of patients. PSAT1 gene encodes the enzyme phosphoserine aminotransferase implicated to serine biosynthesis and has been linked with cell proliferation and increasing mRNA expression in colorectal cancer [26]. ANXA1 is a member of annexin superfamily of $\mathrm{Ca}^{2+}$-dependent phospholipid binding proteins. Its gene expression has been studied extensively [27]. Annexin 1 may activate various protein tyrosine kinases [17] and inhibit cytosolic phospholipase A2 and cyclooxygenase, thus exhibiting antipyretic and anti-inflammatory activity. Our studies showed that $\boldsymbol{A N X A 1}$ expression might have an anti-inflammatory protective effect on bladder early tumorigenesis rather than a signalization function.

Two genes (PLOD2 and WDR72) validated and found to have a higher gene expression (see Table 2) in the group with recurrence compared to the group without recurrence were identified in bladder cancer for the first time. The enzyme PLOD2 catalyzes the hydroxylation of lysyl residues in collagen-like peptides and thus it is critical for the stability of intermolecular cross-links. It may cause a decrease of a differentiation degree of UC [28]. No data were published about a role of the WDR72 protein in malignancies. The WDR34 and WDR72 genes encode proteins that facilitate formation of heterotrimeric or multiprotein complexes. The WDR proteins may function as molecular adaptors for substrate recognition, and modulate multiple biological processes through ubiquitindependent proteolysis.

Limitations of this study include the retrospective nature of sample collections, small sample size and non-homogenous study sample. Samples used in this study were grossly dissected, and the distinction between epithelial and stromal components was not made. cDNA microarray need complicated steps of statistical data analysis. The different statistical methodologies may hamper reproducibility and might also lead to considerable false discovery rate. Therefore the array experiments should be repeated or validated using other techniques for RNA expression quantification.

For reliable validation of cDNA microarray results by RT Q-PCR two distinct tissue samples need to display at least a 3-fold difference in gene expression in the microarray experiment. Since cDNA microarray analysis is still a laborious, complicated and expensive technique that needs relative large amounts of RNA, usually a small number of patients is studied. The qRT-PCR provides the possibility of further studying the genes of interest identified by microarray in larges series. Moreover, qRT-PCR permits the analysis of a low amount of and even poor quality RNA [15].

We tried to reduce the limits of our study in heterogeneity and quality of biological samples by using an elaborated RNA 
isolation method and obtaining several tissues core biopsies. Evaluation of a putative role of selected genes in bladder tumorigenesis was very difficult and some suggestions in Discussion border on speculations. Further studies, especially on signal transduction at the molecular level are required for further clarification of the mechanistic role of selected genes in tumor recurrence of urinary bladder UCs and expression results need to be confirmed in large cohort of patients and longer time of follow-up.

We recognized genes that were differently expressed in NMIBC. This set of genes may serve as a promising pool of candidates coding for molecular markers of very early stage of primary NMIBC elucidating the earliest tumorigenic events in bladder cancer now. Future research is directed at validation of promising molecular markers in larger cohorts of patient tumor samples in urine and in bladder premalignancies and early-stage NMIBC. Identifying the set of potential candidate genes differently expressed in superficial bladder tumors is the first step towards developing a panel of marker genes for bladder cancer prognosis.

Acknowledgements: This study was supported by the Research Grant VZ MSM00216200808 and NT12417. We thank Mrs A. Soukupova, dr B. Ebner and dr C. Guelly for excellent technical assistance.

\section{References}

[1] http://www.svod.cz/

[2] PARKIN DM, BRAY F, FERLAY J, PISANI P Global cancer statistics, 2002. CA Cancer J Clin 2005; 55: 74-108. http:// dx.doi.org/10.3322/canjclin.55.2.74

[3] BLAVERI E, SIMKO JP, KORKOLA JE, BREWER JL, BAEHNER F et al. Bladder cancer outcome and subtype classification by gene expression. Clin Cancer Res 2005; 11: 4044-4055. http://dx.doi.org/10.1158/1078-0432.CCR-04$\underline{2409}$

[4] LANDIS SH, MURRAY T, BOLDEN S, WINGO PA Cancer statistics, 1999. CA Cancer J Clin 1999; 49: 8-31. http:// dx.doi.org/10.3322/canjclin.49.1.8

[5] LAMM DL Long-term results of intravesical therapy for superficial bladder cancer. Urol Clin North Am 1992; 19: 573-580.

[6] BABJUK M, SOUKUP V, MARES J, DUSKOVA J, PECEN $\mathrm{L}$ et al. Association of PAX5 expression with clinical outcome in patients with TaT1 transitional cell carcinoma of the bladder. Urology 2006; 67: 756-761. http://dx.doi. org/10.1016/j.urology.2005.10.053

[7] SANCHEZ-CARBAYO M, SOCCI ND, LOZANO J, LI W, CHARYTONOWICZ E et al. Gene discovery in bladder cancer progression using cDNA microarray. Am J Pathol 2003; 163: 505-516. http://dx.doi.org/10.1016/S0002-9440(10)63679-6

[8] DYRSKJOT L, ZIEGER K, KRUHOFFER M, THYKJAER T, JENSEN JL et al. A molecular signature in superficial bladder carcinoma predicts clinical outcome, Clin Cancer Res 2005; 11: 4029-4036. http://dx.doi.org/10.1158/1078-0432.CCR04-2095
[9] SOBIN LH, WITTEKIND C In: Sobin LH, Wittekind C, editors. UICC TNM classification of malignant tumors, 5th ed., New York: Wiley Liss, 1997: 187-190.

[10] STONE R II, SABICHI A, GILL G, LEE IL, ADEGBOYEGA $P$ et al. Identification of genes correlated with early stage bladder cancer progression. Cancer Prev Res 2010; 3: 776-786. http://dx.doi.org/10.1158/1940-6207.CAPR-09-0189

[11] SANCHEZ-CARBAYO M, SOCCI ND, CHARYTONOWICZ E, LU M, PRYSTOWSKY M et al. Molecular profiling of bladder cancer using cDNA microarrays: defining histogenesis and biological phenotypes. Cancer Res 2002; 62: 6973-6980.

[12] KIM WJ, KIM EJ, KIM SK, KIM YJ, HA YS et al. Predictive value of progression-related gene classifier in primary non-muscle invasive bladder cancer. Mol Cancer 2010; 9: 3. http://dx.doi.org/10.1186/1476-4598-9-3

[13] ELSAMMAN E, FUKUMORI T, EWIS AA, ALI N, KAJIMOTO $\mathrm{K}$ et al. Differences in gene expression between noninvasive and invasive transitional cell carcinoma of human bladder using complementary deoxyribonucleic acid microarray: preliminary report. Urol Oncol 2006; 24: 109-115. http://dx.doi.org/10.1016/j.urolonc.2005.07.011

[14] KAWAKAMI K, ENOKIDA H, TACHIWADA T, GOTANDA $\mathrm{T}$, TSUNEYOSHI $\mathrm{K}$ et al. Identification of differentially expressed genes in human bladder cancer through genome-wide gene expression profilling. Oncol Rep 2006; 16: 521-531.

[15] SCHULTZ IJ, WESTER K, STRAATMAN H, KIEMENEY LA, BABJUK $M$ et al. Prediction of recurrence in Ta urothelial cell carcinoma by real-time quantitative analysis: A microarray validation study. Int J Cancer 2006; 119: 1915-1919. http:// dx.doi.org/10.1002/ijc.22059

[16] RIESTER M, TAYLOR JM, FEIFER A, KOPPIE T, ROSENBERG JE et al. Combination of a novel gene expression signature with a clinical monogram improves the prediction of survival in high-risk bladder cancer. Clin Cancer Res 2012; 18: 1323-1333. http://dx.doi.org/10.1158/1078-0432.CCR-11$\underline{2271}$

[17] LIM LH, PERVAIZ S Annexin 1: the new face of an old molecule. FASEB J 2007; 21: 968-975. http://dx.doi.org/ 10.1096/fi.06-7464rev

[18] KRAUSE S, HINDERLICH S, AMSILI S, HORSTKORTE R, WIENDL $\mathrm{H}$ et al. Localization of UDP-GlcNAc 2-epimerase/ ManAc kinase (GNE) in the Golgi complex and the nucleus of mammalian cells. Exp Cell Res 2005; 304: 365-379. http:// dx.doi.org/10.1016/j.yexcr.2004.11.010

[19] SUGITA S, JANZ R, SUDHOF TC Synaptogyrins regulate Ca2+-dependent exocytosis in PC12 cells. J Biol Chem 1999; 274: 18893-18901. http://dx.doi.org/10.1074/ jbc.274.27.18893

[20] ZHANG N, SANDERS AJ, YE L, KYNASTON HG, JIANG WG Expression of vascular endothelial growth inhibitor (VEGI) in human urothelial cancer of the bladder and its effect on the adhesion and migration of bladder cancer cells in vitro. Anticancer Res 2010; 30: 87-95.

[21] CHAN DW, CHAN CY, YAM JW, CHING YP, NG IO Prickle-1 negatively regulates Wnt/beta-catenin pathway by promoting Dishevelled ubiquitination/degradation in liver 
cancer. Gastroenterology 2006; 131: 1218-1227. http://dx.doi. org/10.1053/j.gastro.2006.07.020

[22] WANG L, ZHU JS, SONG MQ, CHEN GQ, CHEN JL Comparison of gene expression profiles between primary tumor and metastatic lesions in gastric cancer patients using laser microdissection and cDNA microarray. World J Gastroenterol 2006; 12: 6949-6954.

[23] LETO TL, FORTUGNO-ERIKSON D, BARTON D, YANGFENG TL, FRANCKE U et al. Comparison of nonerythroid alpha-spectrin genes reveals strict homology among diverse species. Mol Cell Biol 1988; 8: 1-9.

[24] CHEN L, ZHU YY, ZHANG XJ, WANG GL, LI XY et al. TSPAN1 protein expression: A significant prognostic indicator for patients with colorectal adenocarcinoma. Word J Gastroenterol 2009; 15: 2270-2276. http://dx.doi. org/10.3748/wjg.15.2270
[25] THIESEN S, KUBART S, ROPERS HH, NOTHWANG HG Isolation of two novel human RhoGEFs, ARHGEF3 and ARHGEF4, in 3p13-21 and 2q22. Biochem Biophys Res Commun 2000; 273: 364-369. http://dx.doi.org/10.1006/ bbrc. 2000.2925

[26] FRIEDRICHS J, ROSENBERG R, MAGES J, JANSSEN KP, MAECKL C et al. Gene expression profiles of different clinical stages of colorectal carcinoma: toward to a molecular genetic understanding of tumor progression. Int J Colorectal Dis 2005; 20: 391-402. http://dx.doi.org/10.1007/s00384-004-0722-1

[27] CASTELAO JE, YUAN JM, GADO-DOMINGUEZ M, YU MC, ROSS RK Non-steroidal anti-inflammatory drugs and bladder cancer prevention. Br J Cancer 2000; 82: 1364-1369.

[28] FRANK GA, ZAVALISHINA LE, ANDREEVA IuIu Status of extracellular matrix and adhesion markers in urothelial cancer of the urinary bladder. Arkh Patol 2005; 67: 11-14. 